\title{
Diaphragm Activity in Obesity
}

\author{
RuY V. LOURENÇO \\ From the Department of Medicine, University of Illinois College of Medicine \\ and The Hektoen Institute for Medical Research, Chicago, Illinois 60680
}

A B S T R A C T Diaphragm activity during carbon dioxide breathing and total chest compliance during diaphragm relaxation were measured in eight obese subjects : four with normal blood gases and four with hypercapnia and hypoxemia. Whereas there were no significant differences in the values of total chest compliance between the two groups, there were marked differences in diaphragm activity. The increase in integrated electrical activity in the diaphragm, per millimeter increment in carbon dioxide tension in the arterial blood, averaged 66 units (range: 48-90) in the obese-normal subjects and 17 units (range: 12-22) in the obese-hypoventilation subjects. These results suggest that an incapacity to increase the activity in the respiratory muscles, to levels necessary to overcome the load caused by obesity, plays a major role in the genesis of respiratory failure in obese subjects.

\section{INTRODUCTION}

Respiratory failure appears in certain obese subjects producing the obesity-hypoventilation or Pickwickian syndrome $(1,2)$. It is generally accepted that increased mass loading of the ventilatory apparatus (chest wall and lungs) plays a role in the genesis of respiratory failure by causing either an insurmountable load to the respiratory muscles (3) or significant ventilation-perfusion inequalities (4). However, other factors must also be important since not all subjects with unusually large body weight have respiratory failure $(5 a)$, and reduction in weight is not always accompanied by a parallel improvement of the failure (6). Therefore, it has been speculated $(5 a, b, 6)$ that the ability of the respiratory centers to increase the nervous drive of the respiratory muscles to overcome the abnormal mechanical load also plays a role.

The present study is an attempt to define the roles of the increased load on the ventilatory apparatus and of the drive to the respiratory muscles in the production of

Received for publication 21 October 1968 and in revised form 27 March 1969. respiratory failure in obesity. For this purpose, total chest compliance and electrical activity in the diaphragm were measured in subjects with similar degrees of obesity, but differentiated by the presence or absence of respiratory failure.

Furthermore, the results were compared with those obtained in chronic obstructive lung disease, a condition in which mechanical abnormalities of the ventilatory apparatus of a different type from those found in obesity play a role in the establishment of respiratory failure (7).

\section{METHODS}

Eight subjects weighing at least $300 \mathrm{lb}$. and without clinical or radiological evidence of bronchopulmonary disease were studied. Four subjects had normal arterial blood gases (group I) and four had abnormally low oxygen and abnormally high carbon dioxide tensions (group II).

Physical characteristics and respiratory function data are summarized in Table I. Total lung and vital capacities were slightly reduced in the majority of subjects. Forced expiratory volume was within normal limits in all subjects. Single breath diffusing capacity was normal in all subjects but one (M. S.), in whom it was slightly decreased. There were no significant differences between values of respiratory function obtained in patients with normal and abnormal arterial blood gases.

The design of our study included measurements of minute ventilation, diaphragm activity, and total chest compliance.

Minute ventilation and diaphragm activity were measured in all subjects during rebreathing. The subjects were connected to a closed circuit consisting of a pneumotachograph ${ }^{1}$ connected to a 13 liter balloon half filled with $100 \%$ oxygen. Tidal volume, diaphragmatic electromyogram, and integrated electrical activity were recorded continuously on an oscilloscope recording apparatus. ${ }^{2}$

Tidal volume was obtained by electrical integration of the flow signal from a differential strain gauge ${ }^{8}$ connected to the pneumotachograph. The diaphragmatic electromyogram was recorded with a bipolar lead introduced, under fluoroscopy, via the esophagus to the level of the diaphragm (8). The

${ }^{1}$ Adult Model, Electronics for Medicine, Inc., White Plains, N. Y.

'Model DR8, Electronics for Medicine, Inc., White Plains, N. Y.

'Model PM5, 0.2-350, Statham Transducers, Inc., Hato Rey, Puerto Rico. 
TABLE I

Physical Characteristics and Respiratory Function in Eight Obese Subjects*

\begin{tabular}{|c|c|c|c|c|c|c|c|c|c|}
\hline \multirow[b]{2}{*}{ Subject } & \multirow[b]{2}{*}{ Sex } & \multirow[b]{2}{*}{ Age } & \multirow[b]{2}{*}{ Height } & \multirow[b]{2}{*}{ Weight } & \multirow{2}{*}{$\begin{array}{r}\text { Total lung } \\
\text { capacity }\end{array}$} & \multirow{2}{*}{$\begin{array}{c}\text { Vital } \\
\text { capacity }\end{array}$} & \multicolumn{2}{|c|}{$\begin{array}{l}\text { Forced expiratory } \\
\text { volume }\end{array}$} & \multirow{2}{*}{$\begin{array}{c}\begin{array}{c}\text { Diffusing } \\
\text { capacity }\end{array} \\
\begin{array}{c}\text { Single } \\
\text { breath }\end{array}\end{array}$} \\
\hline & & & & & & & $1 \mathrm{sec}$ & $3 \mathrm{sec}$ & \\
\hline \multicolumn{10}{|c|}{ Group I Obese-Normal } \\
\hline M. A. & $\mathbf{M}$ & 38 & 69 & 377 & $\begin{array}{c}7.56 \\
(6.70)\end{array}$ & $\begin{array}{c}5.36 \\
(4.70)\end{array}$ & 73 & 93 & $\begin{array}{c}27.5 \\
(30.0)\end{array}$ \\
\hline S. C. & $\mathbf{M}$ & 39 & 67 & 360 & $\begin{array}{c}5.06 \\
(6.22)\end{array}$ & $\begin{array}{c}3.70 \\
(4.38)\end{array}$ & 72 & 92 & $\begin{array}{c}26.8 \\
(27.9)\end{array}$ \\
\hline J. N. & $\mathrm{F}$ & 55 & 63 & 303 & $\begin{array}{c}4.26 \\
(4.56)\end{array}$ & $\begin{array}{c}2.82 \\
(2.96)\end{array}$ & 77 & 96 & $\begin{array}{l}18.6 \\
(16.5)\end{array}$ \\
\hline M. F. & $\mathrm{F}$ & 50 & 61 & 308 & $\begin{array}{r}3.99) \\
(4.23)\end{array}$ & $\begin{array}{c}3.08 \\
(2.79)\end{array}$ & 70 & 93 & $\begin{array}{c}19.3 \\
(15.8)\end{array}$ \\
\hline \multicolumn{10}{|c|}{ Group II Obese-Hypoventilation } \\
\hline G. G. & $\mathbf{M}$ & 47 & 70 & 353 & $\begin{array}{c}7.06 \\
(6.81)\end{array}$ & $\begin{array}{c}4.55 \\
(4.61)\end{array}$ & 81 & 99 & $\begin{array}{c}31.9 \\
(29.0)\end{array}$ \\
\hline M. S. & $\mathrm{F}$ & 47 & 64 & 315 & $\begin{array}{c}4.31 \\
(4.86)\end{array}$ & $\begin{array}{c}2.77 \\
(3.25)\end{array}$ & 73 & 95 & $\begin{array}{c}15.8 \\
(20.2)\end{array}$ \\
\hline L. D. & $\mathbf{M}$ & 41 & 71 & 325 & $\begin{array}{c}6.70 \\
(7.15)\end{array}$ & $\begin{array}{c}4.52 \\
(4.98)\end{array}$ & 75 & 97 & $\begin{array}{c}29.5 \\
(32.1)\end{array}$ \\
\hline R.F. & $\mathbf{M}$ & 44 & 65 & 320 & $\begin{array}{c}4.70 \\
(5.68)\end{array}$ & $\begin{array}{c}3.85 \\
(3.90)\end{array}$ & 77 & 96 & $\begin{array}{c}26.3 \\
(24.1)\end{array}$ \\
\hline
\end{tabular}

VC, vital capacity.

* Predicted normal values for the respiratory function tests $(5 b)$ are indicated in parentheses.

signal was amplified in a differential amplifier ${ }^{4}$ and integrated in a feedback integrator. As the resulting integrated activity included a cardiac as well as a diaphragmatic component, the former was subtracted (9).

Determinations of $\mathrm{pH}$, oxygen, and carbon dioxide tensions were obtained from brachial artery samples collected at rest and at 90,180 , and $270 \mathrm{sec}$ of the rebreathing period. Minute ventilation and diaphragm activity per minute were calculated by multiplying the rate of breathing by the average tidal volume and by the average integrated electrical activity per breath, respectively. The values obtained during the sampling of arterial blood $(30-60 \mathrm{sec})$ in the rebreathing period were used for the determination of ventilatory and diaphragmatic responses. For the purpose of this paper, ventilatory response is defined as the increment in minute ventilation (in liters per minute) caused by $1 \mathrm{~mm}$ change in arterial blood carbon dioxide tension, and diaphragmatic response, as the increment in integrated electrical activity in the diaphragm (in millivolts-seconds per minute) by $1 \mathrm{~mm}$ of change in arterial blood carbon dioxide tension. Each ventilatory and diaphragmatic response shown in Table II represents the average of two values obtained on the same day (7).

Total chest compliance was measured by the relaxation method (10) with simultaneous monitoring of diaphragm

4 Model EEP8, Electronics for Medicine, Inc., White Plains, N. Y.

${ }^{5}$ Model ID2, Electronics for Medicine, Inc., White Plains, N. Y. activity (11). For this purpose, a bipolar lead was incorporated in a catheter used for the measurement of intraesophageal pressure. The catheter was introduced, via one nostril, through the esophagus until the electrodes reached the level of the diaphragm, and a distinctive electromyogram, corresponding to inspiration, was recorded. In every subject a minimum of 10 relaxation coordinates was obtained from the functional residual capacity to $1500 \mathrm{ml}$ of inspiratory capacity. This measurement was attempted in all subjects, but in two (J. N. and M. F.) diaphragm relaxation was not obtained and, therefore a reliable determination was not possible.

\section{RESULTS}

The results are summarized in Table II.

The values of arterial blood oxygen and carbon dioxide tensions and $\mathrm{pH}$ collected at rest during room air breathing were normal in all subjects of group I. In the four group II subjects, oxygen tension was abnormally low and carbon dioxide tension abnormally high; the values of $\mathrm{pH}$ were moderately decreased below normal in two subjects (M. S. and L. D.) and normal in the other two.

Chest wall compliance was lower than normal (11) in all subjects. The values obtained in two obese subjects with normal blood gases were not significantly different from those found in four patients with respiratory fail- 
TABLE II

Arterial Blood Gases, Total Chest Compliance, and Ventilatory and Diaphragmatic Responses

to Carbon Dioxide Breathing in Eight Obese Subjects

\begin{tabular}{|c|c|c|c|c|c|c|}
\hline \multirow[b]{2}{*}{ Subject } & \multicolumn{3}{|c|}{ Arterial blood* } & \multirow[b]{2}{*}{$\begin{array}{l}\text { Chest } \\
\text { compliance }\end{array}$} & \multirow[b]{2}{*}{$\begin{array}{l}\text { Ventilatory } \\
\text { responses }\end{array}$} & \multirow[b]{2}{*}{$\begin{array}{l}\text { Diaphrag- } \\
\text { matic re- } \\
\text { sponses }\end{array}$} \\
\hline & $\begin{array}{l}\text { Oxygen } \\
\text { tension }\end{array}$ & $\begin{array}{l}\text { Carbon } \\
\text { dioxide } \\
\text { tension }\end{array}$ & $\mathrm{pH}$ & & & \\
\hline & $m m \mathrm{Hg}$ & $m m H_{g}$ & & liters $/ \mathrm{cm} \mathrm{H}_{2} \mathrm{O}$ & liters/min $/ m m ~ H g$ & $\begin{array}{c}m v-\mathrm{sec} / \mathrm{min} / \\
\mathrm{mm} \mathrm{Hg}\end{array}$ \\
\hline \multicolumn{7}{|c|}{ Group I Obese-Normal } \\
\hline M. A. & 83 & 41 & 7.39 & 0.092 & 1.70 & 90 \\
\hline S. C. & 89 & 36 & 7.42 & 0.135 & 1.92 & 72 \\
\hline J. N. & 76 & 42 & 7.41 & & 2.13 & 48 \\
\hline M. F. & 82 & 38 & 7.40 & & 1.85 & 52 \\
\hline Average & 83 & 39 & 7.40 & 0.114 & 1.90 & 66 \\
\hline \multicolumn{7}{|c|}{ Group II Obese-Hypoventilation } \\
\hline G. G. & 67 & 47 & 7.38 & 0.123 & 1.25 & 18 \\
\hline M. S. & 44 & 51 & 7.35 & 0.056 & 0.91 & 22 \\
\hline L. D. & 49 & 60 & 7.30 & 0.103 & 0.66 & 14 \\
\hline R. F. & 65 & 55 & 7.37 & 0.084 & 0.82 & 12 \\
\hline Average & 56 & 53 & 7.35 & 0.092 & 0.91 & 17 \\
\hline
\end{tabular}

* Sampled at rest during room air breathing.

ure. The shape of the compliance curves was similar in all subjects.

The ventilatory responses were smaller in group II patients (average: 0.91 liters $/ \mathrm{min}$ per $\mathrm{mm} \mathrm{Hg}$; range, 0.66-1.25) than in group I patients (average: 1.90; range, 1.70-2.13). However, in both groups the values were generally lower than those previously found in normals by the same method (7).

The diaphragmatic responses were markedly larger in the obese-normal subjects (average: $66 \mathrm{mv}-\mathrm{sec} / \mathrm{min}$ per $\mathrm{mm} \mathrm{Hg}$; range, 48-90) than in those with hypoventilation (average: 17 ; range, $12-22$ ). The values obtained in group I were significantly larger than those reported in normal nonobese subjects ( 7$)$; the values for group II did not differ significantly from normal.

In Fig. 1 the diaphragmatic responses are plotted against the carbon dioxide tension in the arterial blood sampled at rest during room air breathing; the values obtained in obese subjects are compared with the results previously obtained in 13 patients with chronic obstructive lung disease (with and without hypercapnia) and nine normal subjects (7); also shown are the values for one patient with diffuse pulmonary fibrosis and another with alveolar hypoventilation due to brain stem lesion induced by radiotherapy. The diaphragmatic responses were markedly larger in the four obese subjects with eucapnia than in all other subjects, except for the patient with pulmonary fibrosis. By contrast, the values in the obese subjects with abnormally high carbon dioxide tensions did not differ significantly from those obtained in normal subjects and in patients with obstructive lung disease and eucapnia. Patients with obstructive lung disease and hypercapnia and the patient with alveolar hypoventilation of central origin showed the smallest increments in diaphragmatic activity per minute increment in arterial blood carbon dioxide tension. In general, there was, in the patients studied, an inverse correlation between the diaphragmatic response and the values of resting arterial blood carbon dioxide tension.

The diaphragmatic activity per unit change in minute ventilation (Fig. 2) was significantly increased above normal in all obese subjects; this abnormality was more evident in the subjects with eucapnia than in those with hypercapnia.

\section{DISCUSSION}

The results suggest that the incapacity to increase the activity of the respiratory muscles, to a level necessary to overcome the increased load brought upon the ventilatory apparatus, plays an important role in the establishment of the obese-hypoventilation syndrome. By contrast, the degree of impairment of chest wall compliance does not seem to be the determining factor in the respiratory failure of certain obese subjects.

Other authors (12) have reported lower values of total chest compliance in obese subjects with hypoventilation 


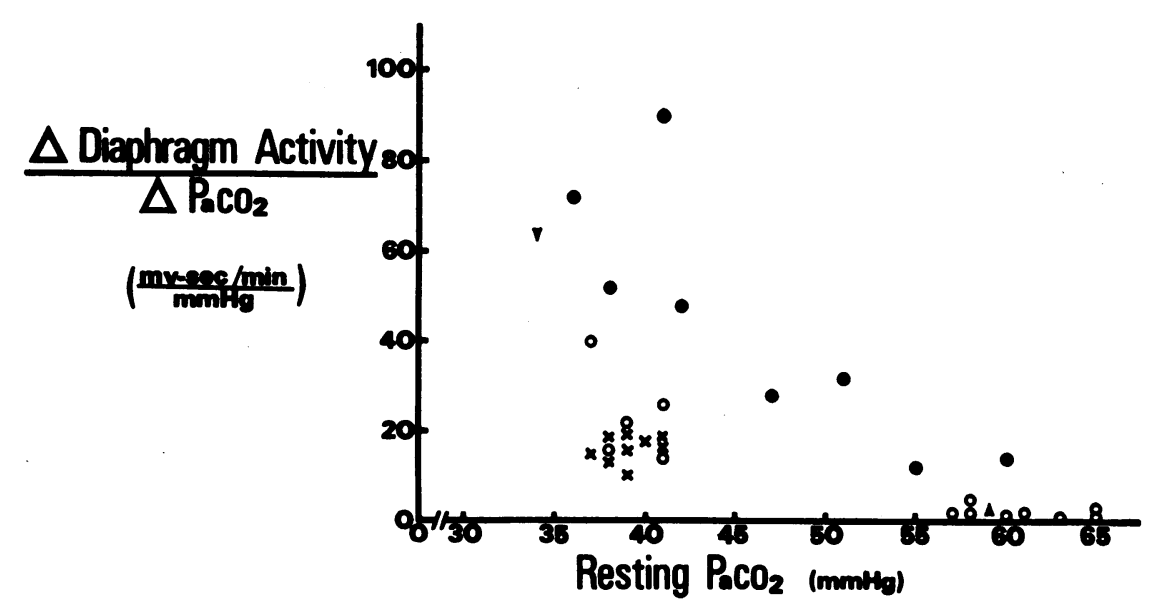

FIGURE 1 Increments in the electrical activity in the diaphragm obtained during carbon dioxide breathing in obese subjects ( $(\bullet)$, normal subjects $(\mathrm{X})$, and in patients with chronic obstructive lung disease $(O)$, diffuse pulmonary fibrosis $(\nabla)$, and brain stem lesion $(\boldsymbol{\Delta})$.

than in those with normal blood gases and have interpreted such findings as indicative of the importance of the mass loading of the ventilatory apparatus in the production of respiratory failure. The present number of measurements is too small to make a similar type of analysis; but our findings of abnormally low compliance in two patients without hypoventilation and of subjects with marked obesity and normal blood gases indicate that the increased mechanical load caused by obesity is not the sole factor in the production of hypoventilation. Furthermore, the frequent presence in other studies ${ }^{\circ}$ (13) of subjects with abnormally low chest compliance in the absence of respiratory failure, agrees with this hypothesis. Another possibility would be that mechanical disadvantages, not shown in the chest compliance measurements, might be present and cause an insurmountable load in certain obese subjects (those with hypoventilation). If this were the case it would be logical to find larger diaphragmatic responses in these patients than in the obese-normal subjects; however, the opposite was true.

As demonstrated in Fig. 1, the increment in diaphragm activity per unit change in carbon dioxide tension in the arterial blood was above normal in the obese-normal subjects and normal in the obese-hypoventilation subjects. It seem unlikely that the positioning of the bipolar lead contributed to the differences in diaphragm activity. The same technique was used for all subjects, the results were reproducible after reintroduction of the lead, and the physical characteristics of the two groups were similar. Also, there is no evidence that morphological abnormalities in the diaphragm, which might explain an unusual pickup of electrical activity in certain obese

\footnotetext{
${ }^{\circ}$ Sharp, J. T. Personal communication.
}

subjects, exist. Instead, the observed disparities in diaphragm activity may be due to differences in the number of nervous impulses coming from the central nervous system through the phrenic nerve (14). In addition, there were no significant differences (in body weight, pulmonary function, and chest wall compliance) in the two groups which could justify disparities in the allocation of the nervous output of the respiratory centers between intercostals and the diaphragm. Therefore, the differences in diaphragm activity probably represent dissimilarities in respiratory center output between obese subjects with and without respiratory failure.

The abnormally high increments in the diaphragmatic activity are conceivably necessary to maintain an adequate alveolar ventilation in the presence of the abnormally low chest compliance. Although the exact mechanism of the increase is not known, it is possible that reflexes coming from the ventilatory apparatus, similar to those described in experimental conditions of increased airway resistance (14), are involved.

The presence, in group II, of diaphragmatic responses similar to those found previously in normal nonobese subjects (7), suggests that the obese-hypoventilation subjects are not capable of augmenting the activity of the diaphragm when the abnormal mechanical load necessitates an increased drive of the respiratory apparatus to maintain adequate alveolar ventilation. It is unlikely that the respiratory centers of the obese-hypoventilation subjects receive less input stimulation from the lungs and(or) chest wall than obese-normals, since there were no significant differences in the ventilatory performance of the two groups. Also, variations in other nervous stimuli reaching the respiratory centers, al- 


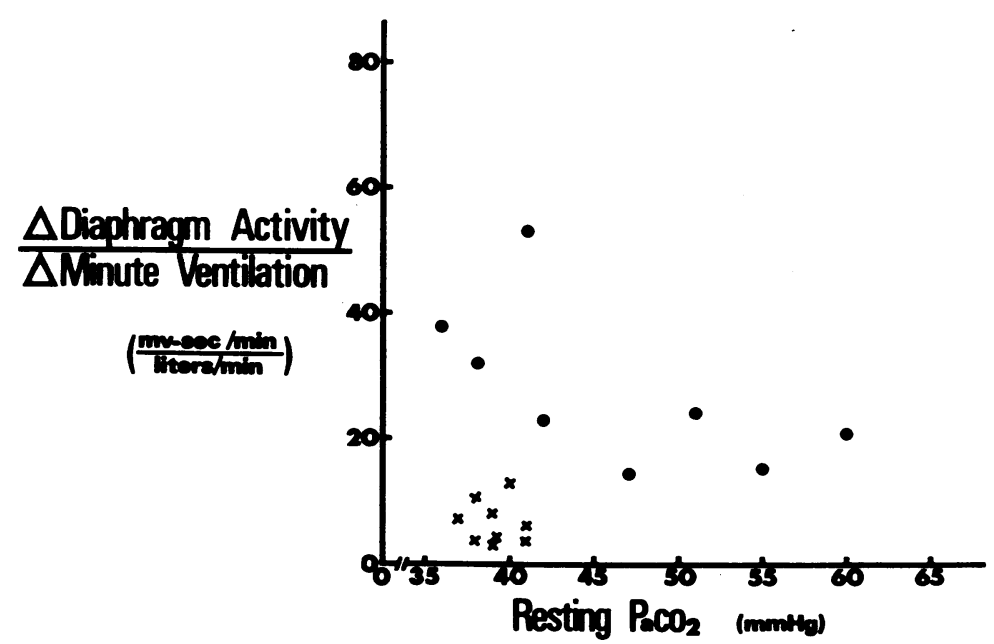

FIGURE 2 Changes in diaphragm activity per liter increment in ventilation in obese $(\bullet)$ and normal subjects $(X)$.

though possible, have not been demonstrated in obese subjects. Lastly, hypoxia, present only in group II subjects, cannot be the cause of their lesser diaphragmatic response, for it would tend to potentiate the carbon dioxide stimulus and not decrease it. Instead, the incapacity to increase diaphragm activity may be secondary to a low sensitivity of the respiratory centers that is known to exist in persons who are otherwise normal $(15,16)$. It is conceivable that, in these persons, the respiratory centers are incapable of increasing their output at the rate demonstrated by obese-normals and by some patients with diffuse pulmonary fibrosis (17), both of whom demonstrate abnormalities of the ventilatory apparatus unaccompanied by alveolar hypoventilation.

An alternative explanation of the respiratory failure and the lesser diaphragmatic responses in patients with Pickwickian syndrome might be that an increased bicarbonate concentration, secondary to chronic hypercapnia, would decrease the responsiveness to carbon dioxide at the level of the central chemoreceptors, in a way similar to that postulated for patients with chronic obstructive lung disease (7). In fact, as shown in Fig. 1, and previously reported in both obstructive lung disease and obesity $(7,18)$, the diaphragmatic response to carbon dioxide breathing is inversely correlated to the level of chronic hypercapnia present. It is possible that this abnormally high bicarbonate concentration plays a role in the perpetuation of the respiratory failure once an initial carbon dioxide retention is produced. However, in order to explain the initial hypercapnia, without incriminating the respiratory centers, it would be necessary to theorize that differences in either the distribution of the mass load or in the intrinsic mechanical characteristics of the lungs or chest wall exist between the two groups of obese subjects. These differences would cause variations in the degree of ventilation-perfusion inequality present, justifying the appearance of carbon dioxide retention only in certain patients. However, there is no evidence of such differences, and the number of obese subjects with hypoventilation seems to be smaller, by far, than that of those with abnormal ventilation and perfusion distributions (4). Moreover, not only are there cases of respiratory failure in obese subjects who lack significant abnormalities in these distributions, but there are also obese-normals with abnormal ventilation-perfusion ratios (4).

Finally, in order to produce the same amount of ventilation, obese subjects needed more diaphragmatic activity than normal subjects (see Fig. 2). This observation is in agreement with the findings of other authors of an augmented oxygen cost of breathing in obese subjects (19). It is possible that the inordinate drive to the diaphragm, present in obese-normals, makes more apparent the mechanical deficiency of the ventilatory apparatus, brought on by obesity. This theory would explain why the group I subjects demonstrated a larger diaphragmatic activity-ventilation ratio than the group II subjects.

\section{ACKNOWLEDGMENTS}

The author wishes to thank Dr. John T. Sharp for the review of this manuscript and Dr. Joseph M. Miranda, Dr. Dario Castellanos, Dr. Michael J. Curtin, Mr. Edward P. Mueller, and Mr. Stephen Y. K. Chung for assistance in this study.

This work was supported by grants No. HE 08902 and No. HE 11805, The National Institutes of Health, U. S. Public Health Service. 


\section{REFERENCES}

1. Auchincloss, J. H., Jr., E. Cook, and A. D. Renzetti. 1955. Clinical and physiological aspects of a case of obesity, polycythemia and alveolar hypoventilation. $J$. Clin. Invest. 34: 1537.

2. Burwell, C. S., E. D. Robin, R. D. Whaley, and A. G. Bickelmann. 1956. Extreme obesity associated with alveolar hypoventilation-a Pickwickian syndrome. Amer. J. Med. 21: 811 .

3. Sharp, J. T., J. P. Henry, S. K. Sweany, W. R. Meadows, and R. J. Pietras. 1964. Effects of mass loading the respiratory system in man. J. Appl. Physiol. 19: 959.

4. Holley, H. S., J. Milic-Emili, M. R. Becklake, and D. V. Bates. 1967. Regional distribution of pulmonary ventilation and perfusion in obesity. J. Clin. Invest. 46: 475.

5. Bates, D. V., and R. V. Christie. 1964. Respiratory Function in Disease; an introduction to the integrated study of the lung. W. B. Saunders Co., Philadelphia. (a) 368 , (b) 92 .

6. Lyons, H. A., and C. T. Huang. 1968. Therapeutic use of progesterone in alveolar hypoventilation associated with obesity. Amer. J. Med. 44: 881.

7. Lourenço, R. V., and J. M. Miranda. 1968. Drive and performance of the ventilatory apparatus in chronic obstructive lung disease. N. Engl. J. Med. 279: 53.

8. Lourenço, R. V., and E. P. Mueller. 1967. Quantification of electrical activity in the human diaphragm. J. Appl. Physiol. 22: 598.

9. Mueller, E. P., and R. V. Lourenço. 1968. On-line subtraction of the cardiac activity from the esophageal electromyogram of the diaphragm. IEEE (Inst. Elec. Electron. Eng.) Trans. Bio-Med. Eng. 15: 115.
10. Rahn, H., A. B. Otis, L. E. Chadwick, and W. O. Fenn. 1946. The pressure volume diagram of the thorax and lung. Amer. J. Physiol. 146: 161.

11. Miranda, J. M., and R. V. Lourenço. 1968. Influence of diaphragm activity on the measurement of total chest compliance. J. Appl. Physiol. 24: 741.

12. Sharp, J. T., J. P. Henry, S. K. Sweany, W. R. Meadows, and R. J. Pietras. 1964. The total work of breathing in normal and obese men. J. Clin. Invest. 43: 728.

13. Naimark, A., and R. M. Cherniack. 1960. Compliance of the respiratory system and its components in health and obesity. J. Appl. Physiol. 15: 377.

14. Lourenço, R. V., N. S. Cherniack, J. R. Malm, and A. P. Fishman. 1966. The nervous output from the respiratory center during obstructed breathing. J. Appl. Physiol. 21: 527.

15. Shaefer, K. E. 1958. Respiratory pattern and respiratory response to $\mathrm{CO}_{2}$. J. Appl. Physiol. 13: 1 .

16. Lambertsen, C. J. 1960 . Carbon dioxide and respiration in acid-base homeostasis. Anesthesiology. 21: 642 .

17. Lourenço, R. V., G. M. Turino, L. A. G. Davidson, and A. P. Fishman. 1965. The regulation of ventilation in diffuse pulmonary fibrosis. Amer. J. Med. 38: 199.

18. Rochester, D. F., and R. M. Goldring. 1968. The contribution of the diaphragm to the energy cost of increasing ventilation in patients with pulmonary insufficiency. Clin. Res. 16: 373. (Abstr.)

19. Fritts, H. W., Jr., J. Filler, A. P. Fishman, and A. Cournand. 1959. The efficiency of ventilation during voluntary hyperpnea; studies in normal subjects and in dyspneic patients with either chronic pulmonary emphysema or obesity. J. Clin. Invest. 38: 1339. 